\title{
Aplicação de atividades experimentais de eletrodinâmica a alunos com deficiência visual
}

\section{Application of experimental activities of electrodynamics with visually impaired students}

\author{
F. L. EvANGELISTA*1 \\ ${ }^{1}$ Instituto Federal de Santa Catarina.
}

\begin{abstract}
Resumo
Este trabalho tem como objetivo a elaboração e análise de uma proposta para discutir o conceito clássico de Corrente Elétrica, junto a estudantes com deficiência visual. Em função da importância para os objetivos da pesquisa, decidiu-se utilizar o registro em forma de áudio para posterior análise dos encontros. Outro instrumento de coleta de dados foi a observação. A partir de atividades experimentais, categorizadas na literatura, foram desenvolvidas algumas adequações ao material e ao procedimento metodológico para o ensaio piloto, aplicado junto a Associação Catarinense de Integração do Cego, ACIC. As avaliações da pertinência destes materiais e do procedimento apresentaram-se como essenciais à reestruturação de uma segunda sequência de ensino. Foi possível apontar algumas características dos materiais e procedimentos, consideradas como relevantes para o auxílio no processo de ensino e aprendizagem de estudantes com e sem deficiência visual no ensino regular.
\end{abstract}

Palavras-chave: Atividades Experimentais. Ensino de Física. Física para Alunos com Deficiência Visual. Inclusão.

*fabio.evangelista@ifc.edu.br 


\begin{abstract}
This work builds and analyses a proposal to discuss the classic electric current concept with visually impaired students. Given the importance for the objectives of the research, it was decided to register the activities in audio for posterior analysis. A pilot study was developed using materials and methodology based in literature about experimental activities and applied at the Associação Catarinense para Integração do Cego, ACIC. A second teaching syllabus was developed based on the evaluation of the pilot study results. It was possible to pinpoint some features of the materials and procedures which were relevant to aid the learning-teaching process concerning students with and without visual deficiency in regular school context.
\end{abstract}

Keywords: Experimental activities. Physics education. Physics teaching for visually impaired students. Inclusion.

\title{
I. INTRODUÇ̃̃̃O
}

É importante ter noção do que vem a ser uma pessoa com deficiência visual e o que a torna específica. Camargo (2005) afirma que, atitudes consideradas simples para uma pessoa com visão normal, como tomar um ônibus, escolher o que comer em um restaurante, contar dinheiro, ter acesso a informações e frequentar uma sala de aula, se constituem como extremamente complexas, inéditas, extraordinárias, anormais e constrangedoras às pessoas com esta particularidade. Tais especificidades, em algumas situações, são esquecidas, ignoradas, ou ainda, submetidas a um fator místico, que atribui a estas pessoas uma alta sensibilidade, refletida num tipo de "sexto sentido". Na sociedade de maioria vidente, a iniciativa sempre foi a de tentar fazer com que as pessoas com deficiência visual se adequassem a realidade da cultura dominante. "Seria absurdo negar este fato, antes, ele deve ser considerado para que se possam identificar os conceitos, valores, definições de senso comum ditado pelo sentido da visão"(MASINI, 1994 p. 27). Em outras palavras, pode-se dizer que a vida se apresenta organizada por quem vê para os que vêem.

Trabalhos indicam que estudos nessa seara encontram-se em andamento (PIMENTEL e ARAGON, 2019; DE SOUZA e PALMA, 2017; CARNEIRO et al., 2017; LIMA e DE CASTRO CATARINO, 2012), indicando também que não se pode negar ou ignorar a necessidade de uma maior atenção a efetivação social destes sujeitos. Para atender a esse contingente, políticas inclusivas foram desenvolvidas e postas em prática, como a Lei de Diretrizes e Bases da Educação (LEI Nž. 9394/96, Artigo 4ž) que defende a entrada e permanência destes alunos ao ensino oferecido pelas escolas e classes regulares públicas. No entanto, professores que não possuem formação específica provavelmente terão contato com estes alunos nas suas salas de aula. Faz-se importante, portanto, capacitá-los sobre como fazê-lo. Neste sentido, este trabalho proporciona um exemplo de uso de materiais didáticos e aplicações de atividades experimentais a fim de auxiliar nesta questão.

Sendo assim, a pergunta que emerge é: Quais características devem conter atividades experimentais para auxiliarem no ensino de eletrodinâmica para estudantes com deficiência 
visual? Neste viés, o presente artigo tem a intenção de indicar um possível caminho para trabalhar o tema corrente elétrica a alunos com deficiência visual. Isto decorreu de uma reunião com a Coordenação Pedagógica da Associação Catarinense de Integração do Cego (ACIC), chegando-se à conclusão que conteúdos vinculados a Eletricidade seriam mais interessantes aos seus alunos. Nesta perspectiva, a preocupação foi desenvolver uma sequência didática com características que permitissem o ensino do referido conteúdo, de modo que também pudesse ser trabalhada concomitantemente com alunos videntes.

\section{Aporte TeÓRICO}

A relevância do senso comum dos estudantes durante o processo de ensino-aprendizagem é algo amplamente difundido. Pietrocola (2001), explica que o senso comum, configurado a partir do histórico de vida de cada pessoa, é delineado por um contexto repleto de crenças, ideais, tradições familiares e culturais, que modificam seu modo de pensar e agir, num mútuo ajuste entre o mundo exterior e interior.

Considerando esta questão, procurou-se durante todo o processo de aplicação da sequência de ensino, levar em conta o que as pesquisas, no ensino cientifico, afirmam sobre o levantamento das pré-concepções também chamadas concepções alternativas, idéias intuitivas, concepções espontâneas, etc.: (COLL et al (1998); VIENNOT, 1979; SOLIS VILLA, 1984; DRIVER, 1986).

Coll et al (1998), salienta que existe um caráter implícito no desenvolvimento do senso comum, mostrando assim que, nem sempre o indivíduo tem consciência da existência de suas concepções.

Greca Moreira (2002) acrescentam que, as concepções alternativas dos estudantes têm significado e funcionalidade para as situações cotidianas, sendo, portanto, resistentes a mudanças, representando um modo mais abrangente de se compartilhar significados, permitindo a comunicação entre vários grupos de diferentes culturas.

Pesquisas mais recentes mostram que o pensamento pouco ou nada mudou com relação a necessidade da utilidade do senso comum no aprendizado do estudante (SIPEC, 2017; SANTOS, 2017; OLIVEIRA, 2018; FACCIO, 2019).

Ao direcionar a atenção para o indivíduo com deficiência visual, Camargo (2005) salienta que, de maneira similar ao vidente, ele acumula experiências de todo o tipo, passando a exigir não apenas o entendimento de situações particulares, mas também do mundo em que vive. Assim sendo, durante todos os encontros os alunos foram previamente questionados sobre os fenômenos envolvidos em cada atividade, na prerrogativa de que contextualizassem e atribuíssem significados aos conceitos trabalhados, para em seguida, dar prosseguimento a intervenção.

\section{II.1. Atividades Experimentais}

Este trabalho amparou-se no conceito desenvolvido por Alves Filho (2000), destinado ao processo de ensino e aprendizagem, denominado Atividades Experimentais. Estas atividades devem ser entendidas como um objeto didático, produto de uma Transposição Didática, de modo que tenha a função de mediar o processo de ensino-aprendizagem. É 
um objeto de ação que, manipulado didaticamente pelo professor, irá facilitar a indução do fenômeno didático que objetiva o ensino de saberes.

Sendo assim, a atividade experimental exige a intervenção do professor a qualquer momento, através de questionamentos, desafios, estímulos e motivações no intuito de aumentar a função ativa do aluno. Esta ideia enfatiza a inexistência de uma receita prescritiva, pois isto definitivamente barraria a espontaneidade do processo, retornando ao modelo tradicional e dogmático, no entanto, não impede que se apontem caminhos.

Pinho Alves (2000) classifica as atividades experimentais em sete categorias, das quais, quatro foram selecionadas para poder trabalhar com a bagagem intelectual dos estudantes com deficiência visual, fora de um contexto escolar, moldadas pelo contorno informal de educação: Atividade Experimental Compartilhada, Modelizadora, Crítica e comprobatória.

\section{II.2. Adequação das Categorias}

No âmbito desta pesquisa, a Tecnologia Assistiva teve um caráter indispensável. Trata-se de um conceito proposto pelo Comitê de Ajudas Técnicas (CAT), uma comarca que "estuda essa área do conhecimento no âmbito da Secretaria Especial dos Direitos Humanos da Presidência da República (SEDH/PR)"(GALVÃO FILHO, 2009, p.115). Em suma, entende-se Tecnologia Assistiva como a uma área do conhecimento interdisciplinar, que inclui produtos, serviços, práticas, estratégias, recursos e metodologias com o intuito de permitir e fomentar a autonomia e inclusão social de sujeitos com qualquer tipo de deficiência (CAT, 2007).

Os instrumentos, embasados por esta Tecnologia, podem atuar como mediações às pessoas com deficiência visual, auxiliando na potencialização da interação social. Tal interação é entendida neste artigo como a necessidade de relacionar-se, de entender e ser entendido, de comunicar-se com os demais, impulsionando o seu desenvolvimento (GALVÃO FILHO, 2009).

Ao se amparar nas categorias de Pinho Alves (2000), é importante lembrar que elas foram pensadas para os videntes, que têm a capacidade de definir um objeto ou situação rapidamente, tanto na sua composição quanto na configuração dos seus contornos. Portanto, para os estudantes com deficiência visual, duas destas categorias foram entendidas de forma diferente, senão, adaptadas para este novo estudante. Deste modo, ao se referir ao manuseio dos materiais, houve a categorização em atividades de compartilhamento e comprobatória.

O compartilhamento vem ao encontro das muitas dificuldades originadas das diferentes interpretações que os estudantes elaboraram sobre o que manuseavam. A prática docente mostrou que os estudantes relutavam em perguntar os significados dos materiais desconhecidos. Aliou-se a isto a limitação atribuída ao sentido tátil, originando interpretações, na maioria das vezes, totalmente distintas. Por vezes, o discurso docente ainda levava o estudante a imaginar coisas desvinculadas do objeto focado. O compartilhamento traz a necessidade de se oferecer condições para que os estudantes consigam perceber um dado elemento da mesma maneira. Para isto, o professor induziu o perceber tátil dos estudantes, levando-os às relações táteis de interesse. Através da respectiva indução didática, direcionaram-se as proposições livres dos alunos, no sentido das proposições de aceitação coletiva.

Esta categoria ainda tem a importância de precursora da atividade modelizadora, crítica 
e comprobatória, pois é certo que, sem a assimilação tátil do concreto, dificultaria-se, senão, inviabilizaria-se a assimilação conceitual proveniente da relação mediadora entre as demais atividades e os conceitos científicos.

Já a comprobatória, assemelha-se a um exercício tradicional de repetição, só que mais rico, pois adiciona à manipulação a memorização dos equipamentos, assegurando a construção de um modelo mental do percebido. O material manuseado não deve ser novidade ao estudante, para assim, atuar como um reforço, uma revisão tátil oferecendo condições de sua utilização em novas situações.

Entretanto, é importante ressaltar, que estas duas atividades táteis, de compartilhamento e comprobatória, servem de base para se alcançar às categorias de Pinho Alves (2000), funcionando como um trampolim, assegurando o acesso aos dados do equipamento e a construção dos saberes.

\section{Metodologia da Pesquisa}

O contato inicial com os estudantes com deficiência visual originou-se da carência na formação acadêmica de Licenciatura em Física para este fim (EVANGELISTA, 2019). Sabendo que a constituição respalda a entrada e permanência de todas as pessoas ao ensino público, percebeu-se a importância das variáveis envolvidas na forma com que estes alunos interagem e reconhecem o mundo a sua volta, como utilizam o material didático e como expressam suas dificuldades ao lidar com o conteúdo físico estudado. Este aspecto refletiu na observação da aprendizagem dos estudantes, levando-se em consideração todo o processo de aplicação e não apenas determinados pontos.

A opção por uma análise fenomenológica surgiu como uma opção para a compreensão dos acontecimentos, de maneira a direcionar a atenção da pesquisa muito mais para o processo do que para o produto. De igual forma, a abordagem de natureza qualitativa da pesquisa (FREITAS, 2016), pareceu ser a mais apropriada para a análise dos fenômenos educacionais vivenciados.

Tal abordagem culminou em uma estratégia para a condução da sequência, composta por cinco procedimentos:

- Adequação das atividades experimentais a fim de permitir interações não visuais.

- Utilização de um processo metodológico que respeitasse as características sensoriais dos alunos com deficiência visual.

- Aplicação das referidas atividades a um grupo de alunos com deficiência visual, seguido pelo registro e análise (sequência piloto).

- Correção e reformulação da sequência didática, dos equipamentos e do procedimento metodológico utilizado.

- Reaplicação das atividades, agora reformuladas, a um novo grupo de alunos com deficiência visual, seguido pelo registro e análise (sequência final). 
Em suma, primeiramente foi desenvolvida e aplicada uma sequência piloto. Após avaliar a pertinência dos materiais didáticos e procedimentos utilizados, houve uma reestruturação, resultando numa nova sequência, planejada e aplicada a outros alunos.

\section{Ensaio Piloto}

O ensaio piloto foi composto por cinco encontros. A sequência didática arquitetou-se da seguinte forma: 1ž Encontro: Primeiras Concepções; 2ž Encontro: Condutores ou Isolantes?; 3ž Encontro: Circuitos Elétricos; 4ž Encontro: Corrente Elétrica e Resistência; 5ž Encontro: Elétrons, Corrente Elétrica e Diferença de Potencial.

De modo geral a intenção foi saber quais as pré-concepções dos estudantes com relação ao tema Eletricidade, verificar até que ponto os alunos conseguiam identificar os diferentes materiais, diferenciar os circuitos fechados dos abertos. Quanto aos sujeitos da pesquisa, contou-se com a participação de seis alunos com idades entre 20 e 35 anos. Destes, três com deficiência visual congênita, dois perderam a visão e um com baixa visão.

A sequência piloto apresentou dois principais objetivos. O primeiro, desenvolver as categorias de análise, construídas a partir das relações aluno-conhecimento mediadas pelos materiais didáticos e procedimentos utilizados. O segundo, analisar e avaliar os limites e possibilidades do material e do procedimento metodológico utilizado, visando a sua reestruturação para a elaboração e aplicação de uma segunda sequência, capaz de ser aplicada junto a estudantes com e sem deficiência visual (EVANGELISTA, 2008).

\section{IV.1. Categorias de Análise}

Adotamos duas categorias de análise - Descrição dos Materiais e Apreensão do Conteúdo, assim entendidas:

Descrição dos Materiais Indica se os materiais são facilmente identificados e se oferecem as condições necessárias para a realização das atividades experimentais da sequência de ensino. Para melhor detalhar esta categoria, sua fundamentação ocorrerá por meio de três subcategorias.

- Operacionalização do material - Até que ponto os materiais apresentados facilitam sua identificação.

- Descrição de eventos - Verificar se ocorre o manuseio dos materiais e equipamentos com facilidade, com a intenção de realizar algum evento (circuito fechado, circuito aberto).

- Propostas de atividades Verificar se as propostas manifestas pelos alunos quanto a realização ou aperfeiçoamentos de atividades.

Apreensão do Conteúdo Observar se os procedimentos utilizados nas atividades auxiliam os estudantes a expressarem seu poder de análise e interpretação das diferentes situações estudadas. Para melhor detalhar esta categoria, sua fundamentação ocorreu por meio de quatro subcategorias. 
- Construindo hipóteses - Classificar as hipóteses elaboradas pelos alunos sobre o assunto estudado.

- Compartilhando conceitos - Averiguar quando o aluno reage a uma hipótese ou pergunta, respondendo por meio de uma frase, palavra ou expressão, corroborando com o que o professor ou colega expôs.

- Questionando conceitos - Identificar o questionamento dos estudantes através de hipóteses ou perguntas, motivadas por questões vindas do professor ou colegas.

- Relação de conceitos com o cotidiano - Classificar o momento onde o estudante contextualizou o fenômeno estudado.

Desta forma, assumiu-se que, para o aluno assimilar os conceitos, ele deveria elaborar hipóteses, compartilhar e/ou questionar os conceitos trabalhados além de contextualizar os fenômenos estudados em sala.

\section{IV.2. Procedimentos}

4.2 Procedimentos: O procedimento utilizado apoiou-se nas contribuições de Masini (1994) e Vygotski (1998). O primeiro, por afirmar serem os sentidos tátil, auditivo, olfativo e do paladar, os mediadores na construção interna de uma noção do mundo externo por estas pessoas. O segundo, por descrever que nestes sujeitos, existe um aumento da memória, da atenção e das atitudes verbais, através do desenvolvimento de uma sobre-estrutura psíquica, derivada de muito esforço e exercício. Associados a estes, apresentaram-se ainda a dimensão sinestésica, progressiva e de memória de reconhecimento tátil-auditivo (HALL, 1981 apud MASINI, 1994), além da necessidade do reconhecimento do ambiente (SOUZA, 2002) e da disposição espacial em que os objetos se encontravam.

Neste viés, resolveu-se entregar o material das atividades aos alunos, para que pudessem ter a noção do que estava ocorrendo em cada momento do encontro, permitindo um período maior para a aquisição dos dados táteis e certa proximidade com o evento ou objeto analisado. A fim de facilitar a familiarização do estudante com os materiais, empregou-se aqueles mais usualmente utilizados no cotidiano, como madeira, metal e papelão. Quando havia a necessidade do uso de equipamentos mais complexos, os alunos realizavam um detalhado reconhecimento tátil do mesmo antes de utilizá-lo.

A disposição espacial dos materiais, não era alterada durante as aulas, proporcionando ao estudante a certeza de que, o material posto em um determinado local permaneceria ali até que fosse necessária a sua retirada. Ao retirar ou inserir algum novo elemento ao ambiente, primeiramente informava-se o que iria ocorrer, para então realizar as mudanças.

\section{IV.3. Materiais Didáticos}

Dentre os equipamentos, optou-se pela utilização de um componente eletrônico chamado buzzer (figura 1a), o qual se comporta de maneira similar a um diodo, permitindo a passagem de corrente elétrica num sentido e no outro não. Quando a passagem da corrente se dá no sentido correto, ele emite um som semelhante a uma sirene, sendo sua intensidade 
sonora diretamente proporcional à intensidade da corrente elétrica que o percorre. Pelo fato de ter uma polaridade definida, colocou-se um nó na extremidade positiva.

Foi construído um tabuleiro (figura 1d) para auxiliar na montagem de circuitos elétricos. Este equipamento oferecia total segurança aos estudantes, evitando a exposição de pontas e cantos afiados. Foi projetado para ser desmontável, sendo constituído por três partes, para que os alunos pudessem montar e desmontar os circuitos sem a intervenção docente.

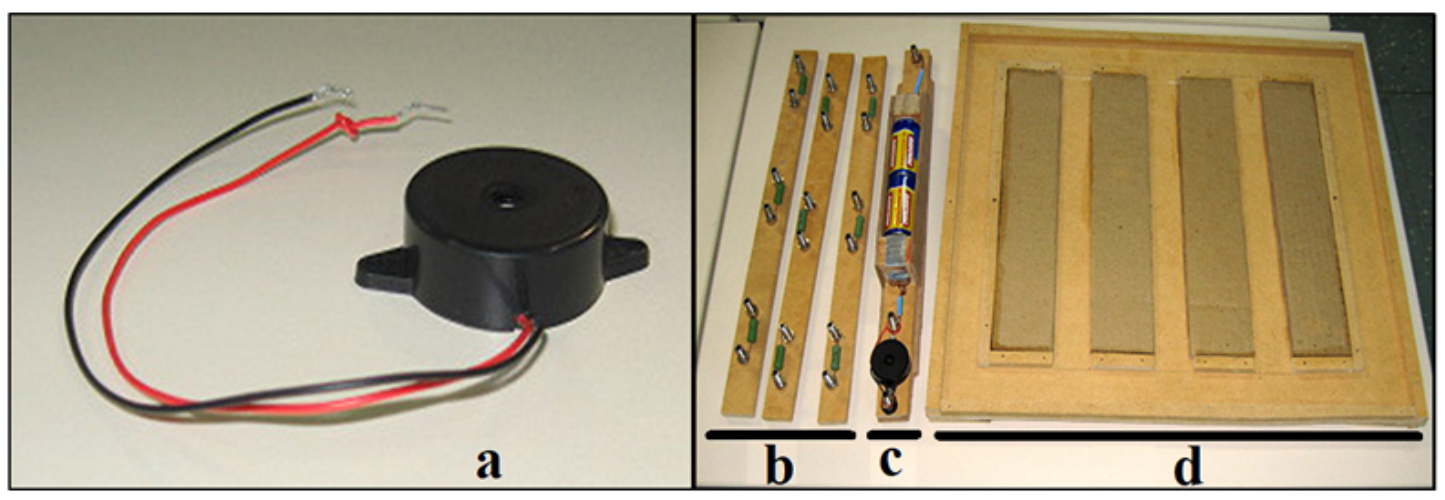

Figura 1: Buzzer e Tabuleiro.

A primeira parte (figura $1 b$ ) foi composta por três tiras de madeira retangulares com três resistores cada, fixados através de pinos de metal. Os três resistores de cada régua tinham a finalidade de induzir ao aluno a idéia de circuito série. A segunda parte (figura 1c), denominada porta-pilhas, tratava-se de uma tira de madeira retangular, com um pino de metal em cada extremidade, que determinavam o ponto de partida e chegada do circuito. Na parte central da régua, havia uma caixa para duas pilhas médias e um buzzer, já fixado. A inserção do buzzer junto ao compartimento das pilhas ocorreu devido a sua polaridade definida. A terceira (figura 1d), chamada base, teve a função auxiliar na montagem de um circuito série ou paralelo através dos desníveis e superfícies com aderências diferentes. As partes altas foram feitas de papelão áspero e as partes baixas de madeira lisa, para auxiliar através do tato nos encaixes das outras partes do equipamento. A intenção foi induzir os estudantes a colocarem os componentes nos vãos existentes. Colocados no centro, formava-se um circuito paralelo, colocados nas bordas, um circuito série.

Para fixar as três partes foram inseridos grampos de metal em formato de "U"(figura 2a) e para interligar o circuito foram utilizados fios com conectores "pino banana"em suas extremidades. 


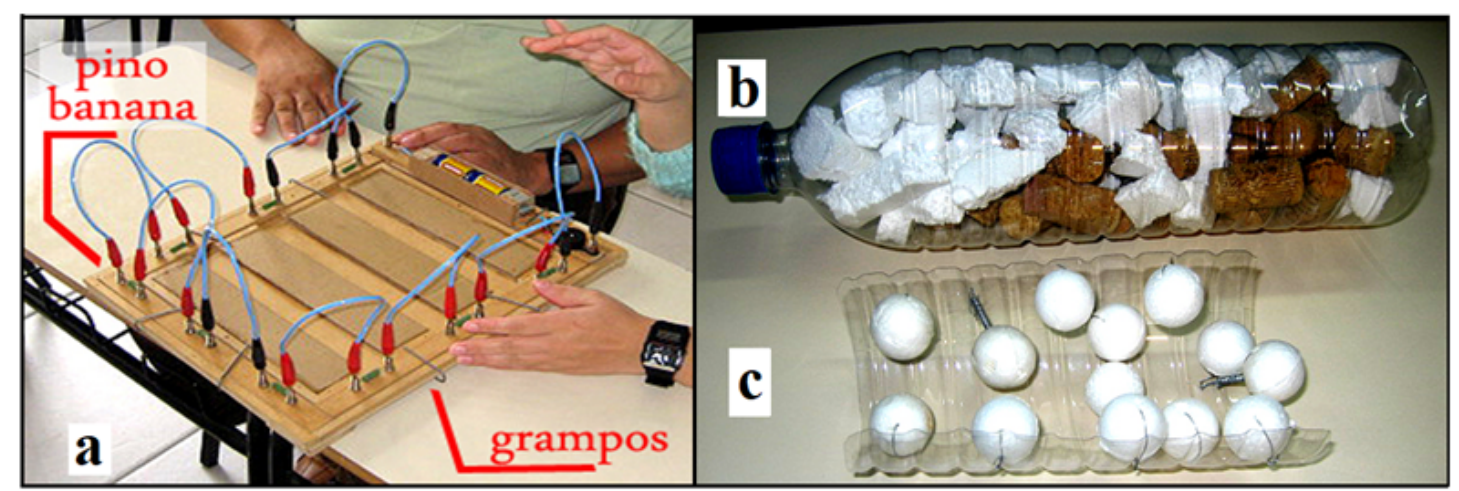

Figura 2: Tabuleiro Montado e Maquetes.

Foram acrescentadas duas maquetes (figura 2b), desenvolvidas no intuito de facilitar a indução do conceito clássico da estrutura cristalina de um fio condutor e da corrente elétrica. A primeira (figura 2c) fez analogia com o fio condutor em circuito aberto. Era composta por uma garrafa PET, com pedaços de isopor e rolhas de cortiça em seu interior. Os alunos, ao "chacoalhá-la", percebiam auditivamente a existência de partes soltas. A ideia é que, conduzidos pelo professor, conseguissem fazer uma analogia aos eletrons livres no fio. A segunda, (figura 2c) consistiu em uma garrafa PET, cortada longitudinalmente ao meio, com esferas de isopor fixadas com arame em seu interior. Estas esferas simulavam os átomos. Os alunos foram convidados a entre passá-los com os dedos de "ponta a ponta", assumindo a função dos elétrons livres. Com isso, pretendeu-se construir uma analogia da movimentação dos elétrons livres em um fio condutor submetido a uma diferença de potencial elétrico, além de relacionar a resistência elétrica às partículas existentes no trajeto.

\section{IV.4. Em Síntese}

As Atividades Experimentais mostraram-se adequadas ao ensino de Eletrodinâmica para os sujeitos em questão. A Compartilhada oportunizou que a partir de um mesmo elemento, os alunos chegassem a respostas semelhantes. A Modelizadora utilizou-se das maquetes para auxiliar na indução do conceito corrente elétrica. A Crítica permitiu a diferenciação dos conceitos corrente elétrica, energia elétrica e diferença de potencial elétrico. A Comprobatória auxiliou na fixação dos conceitos através das revisões realizadas.

Os alunos referiram-se a elementos do seu cotidiano, questionaram as explicações realizadas pelos colegas, compartilharam concepções e construíram hipóteses. Isto se deve, em parte, a opção metodológica adotada: materiais entregues progressivamente e sucessivas revisões. O professor procurou ainda dar voz aos estudantes, visando com isto, provocar questionamentos e promover situações que fomentassem a troca e a construção de hipóteses.

Todos os materiais foram reconhecidos tatilmente. A inserção do buzzer, inicialmente provocou certa dificuldade em sua utilização, porém, com suas repetidas solicitações, foi bem aceito pelos alunos. A robustez das partes do tabuleiro também obteve relevância, permitindo que os alunos manuseassem os mesmos, sem receio de quebrá-los ou danificá-los. As duas maquetes, se mostraram eficazes, auxiliando nas analogias através da identificação tátil e descrição dos materiais. 
No entanto, os termos/conceitos científicos não foram assimilados a contento. A ordem da sequência didática apresentou limitações, pois o conceito de corrente elétrica foi abordado apenas no último encontro. Houve ainda a contaminação das respostas orais dos alunos pelos colegas. O tempo despendido para o reconhecimento do tabuleiro foi muito grande e a liberdade dos alunos ficou comprometida, dificultando a realização de ações voluntárias e sugestões espontâneas de novas configurações para o circuito.

Para um ambiente onde alunos com e sem deficiência visual convivam, a reestruturação da sequência didática se faz indispensável. Deve-se ter equipamentos e estratégias metodológicas que utilizem ambos os sentidos, tato e visão, e equiparem o tempo de reconhecimento dos materiais e as realizações das atividades, ou pelo menos, minimizem esta discrepância. Nesta direção é que foi reorganizada a sequência didática como segue.

\section{Readequações da Sequência Proposta e dos Materiais}

A partir das observações e registros no ensaio piloto, nosso objetivo maior foi reestruturar os equipamentos e os procedimentos metodológicos, de modo a permitir sua utilização tanto por alunos com deficiência visual quanto por videntes, isto é, em classe regulares. Para isto, fez-se alterações, resultando num plano de aulas composto por cinco encontros de uma hora de duração culminando em uma avaliação final, realizada separadamente com cada aluno em horários diferentes. Os encontros foram realizados semanalmente, nas segundas e quintas-feiras. A nova sequência didática e as alterações propostas em relação ao ensaio piloto estão na tabela abaixo, para efeitos comparativos;

Tabela 1: Encontros.

\begin{tabular}{|l|l|}
\hline [HTML]A6A6A6 Ensaio Piloto & Nova Sequência Didática \\
\hline 1ž Encontro: Primeiras Concepções. & 1ž Encontro: Primeiras Concepç̃̃es. \\
\hline 2ž Encontro: Condutores ou Isolantes? & 2ž Encontro: Condutores ou Isolantes, Circuito Fechado ou Aberto? \\
\hline 3ž Encontro: Circuitos Elétricos. & 3ž Encontro: A Corrente Elétrica em Nível Atômico. \\
\hline 4ž Encontro: Corrente Elétrica e Resistência Elétrica. & 4ž Encontro: Corrente Elétrica, Resistência Elétrica e Diferença de potencial elétrico. \\
\hline 5ž Encontro: Elétrons, Corrente Elétrica e Diferença de potencial elétrico. & 5ž Encontro: Circuitos Elétricos Residenciais. \\
\hline Não houve uma avaliação final. & Avaliação. \\
\hline
\end{tabular}

Nesta sequência trabalhamos com 4 alunos com idades entre 19 e 24 anos, todos voluntários. Três deles perderam a visão quando ainda crianças e um apresentava baixa visão (5\%). A seguir, detalhes sobre as modificações realizadas no procedimento metodológico e nos materiais didáticos.

\section{V.1. Procedimentos}

Além das estratégias metodológicas já citadas, inseriram-se outras duas. A "leitura interativa"e o uso de tampas de garrafa pet na aplicação dos questionários.

Quanto à leitura, utilizou-se de textos retirados do GREF (1991). O intuito foi inserir os termos científicos já a partir do primeiro encontro, a fim de torná-los mais familiares aos estudantes. Durante a leitura, o professor oportunizava interações, promovendo constantes momentos que requisitavam a participação ativa dos estudantes durante a leitura. Deste modo, proporcionou-se a ocorrência de uma "leitura interativa", atribuindo aos alunos à condição de agentes ativos no processo. Este procedimento surgiu como uma alternativa, a 
fim de manter os alunos atentos, relacionando o conceito lido com os materiais e atividades realizadas, procurando desta forma, auxiliar na elucidação dos significados terminológicos, eventos e relações Físicas.

Os questionários, retirados de Evangelista (2019), lidos pelo professor aos alunos, apresentaram o objetivo de revisar o assunto tratado no encontro anterior, revisar o assunto trabalhado ao fim do encontro e levantar as hipóteses discentes antes da montagem dos circuitos. As respostas foram obtidas por intermédio de três tampas de garrafa PET, postas sobre a mesa, que representaram as alternativas a, b e c. A tampa referente a alternativa escolhida como resposta, deveria ser virada ao contrário pelo estudante (boca para cima). Deste modo, além de inibir a contaminação das respostas dos alunos pelos colegas, atribuiu-se um caráter dinâmico, divertido e descontraído aos questionários.

\section{V.2. Materiais Didáticos}

Os materiais foram totalmente reconfigurados, porém, respeitando as características tidas como pertinentes; indução quanto a sua montagem, liberdade no seu manuseio, segurança, resistência mecânica e durabilidade. A seguir, as principais modificações realizadas para nova sequência.

O limite espacial oferecido pelo tabuleiro foi transferido para a mesa do aluno através de tiras de borracha E.V.A fixadas em suas bordas (Em rosa na figura 3a). A ênfase atribuída a contextualização dos assuntos trabalhados, contou com o auxílio de aparelhos e equipamentos eletro-eletrônicos utilizados em todos os encontros, chuveiros elétricos, motores elétricos CC de doze volts, rádios CC de três volts, ebulidores elétricos , tomadas, fios com plugs e interruptores (figura $3 b$ ).

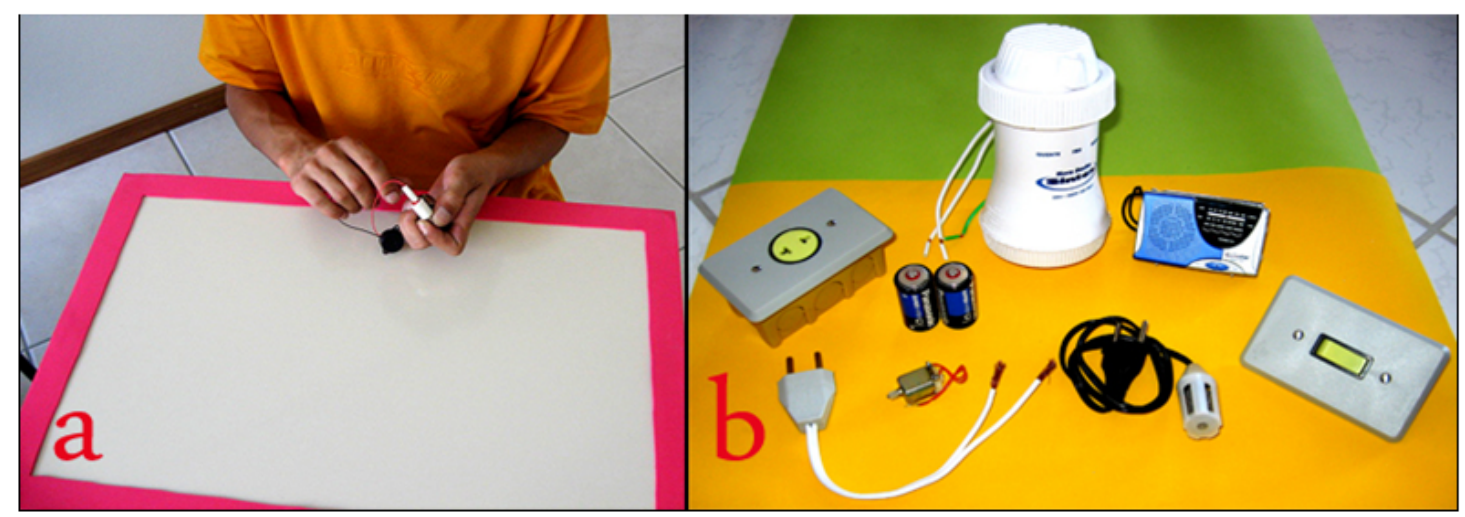

Figura 3: Limite da mesa e eletro-eletrônicos.

Ao se tratar das fontes, foram utilizadas tomadas elétricas residenciais (figura $4 \mathrm{~b}$ ), compostas por duas pilhas ligadas em série (figura 4b1) fixadas atrás da tomada por uma capa plástica (figura 4b2). O pólo positivo foi indicado com fita crepe (figura 4b3). Também houve modificação no porta-pilhas (figura 4a), inserindo dois conectores RCA fêmeas nas extremidades. 


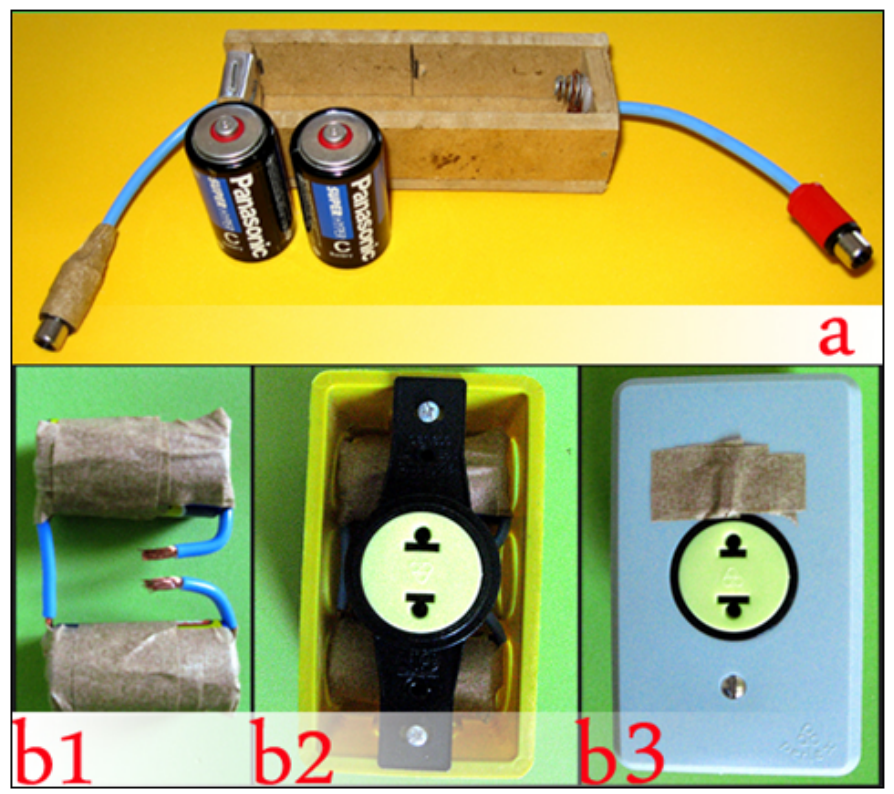

Figura 4: Fontes elétricas.

Aos interruptores (figura 5a), fio com plug (figura 5b) e tomadas (figura $5 c$ ) foram acrescentados dois conectores RCA fêmeas nas extremidades. Os interruptores e as tomadas foram apresentados de maneira a permitir que seus terminais de conexão fossem percebidos tatilmente. A região referente a parte positiva foi indicada com fita crepe.

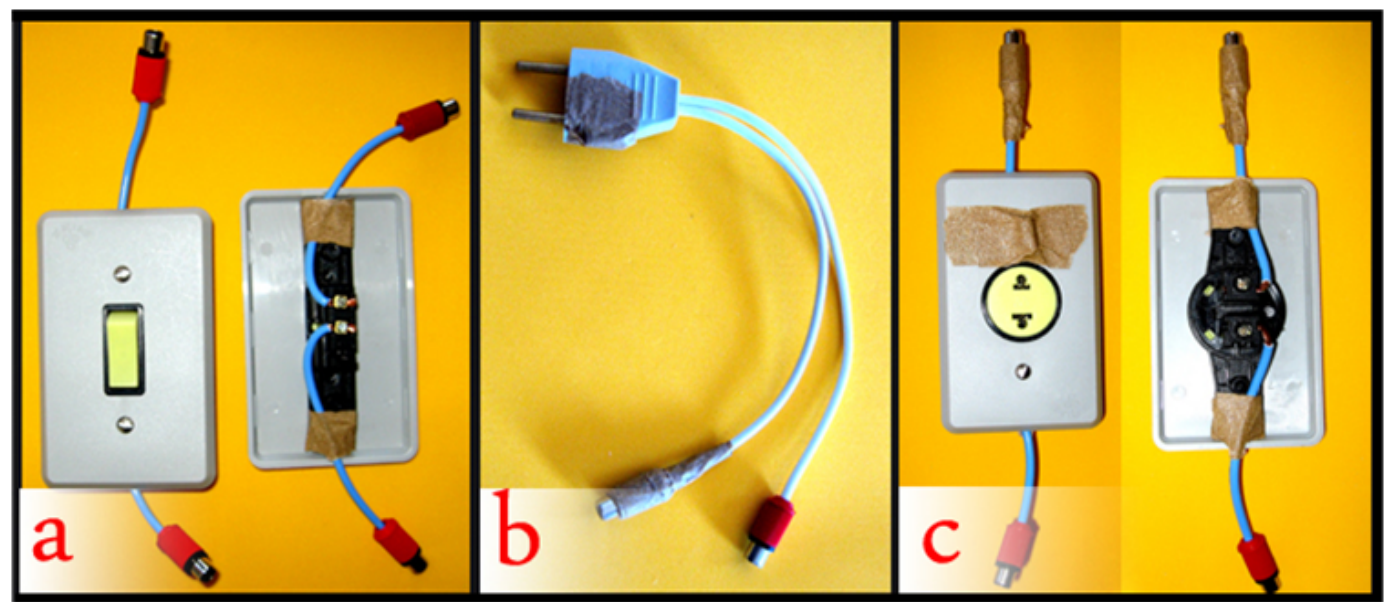

Figura 5: : Interruptores, fio com plug e tomadas.

O buzzer (figura 6a) foi empregado separadamente nas atividades, com dois conectores RCA fêmea. Ao rádio (figura $6 b$ ) foi inserido um fio com plug, para permitir sua conexão à tomada. Em ambos os casos a polaridade positiva foi identificada com fita crepe. 


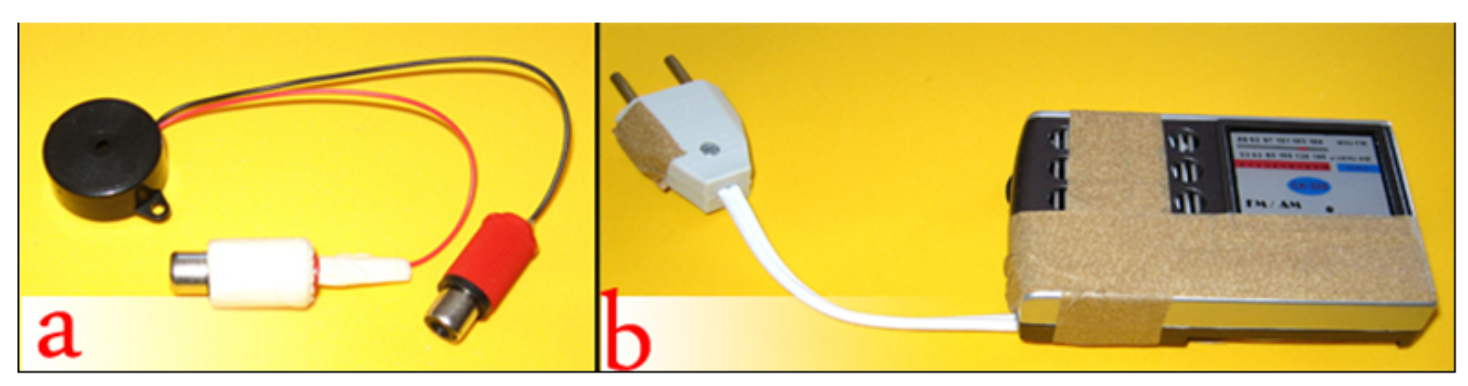

Figura 6: Buzzer e rádio.

Os resistores (figura 7c) foram apresentados de forma independentes, por meio de duas resistências distintas, representadas pelas diferentes aderências, provindas de cilindros feitos com papel-lixa.

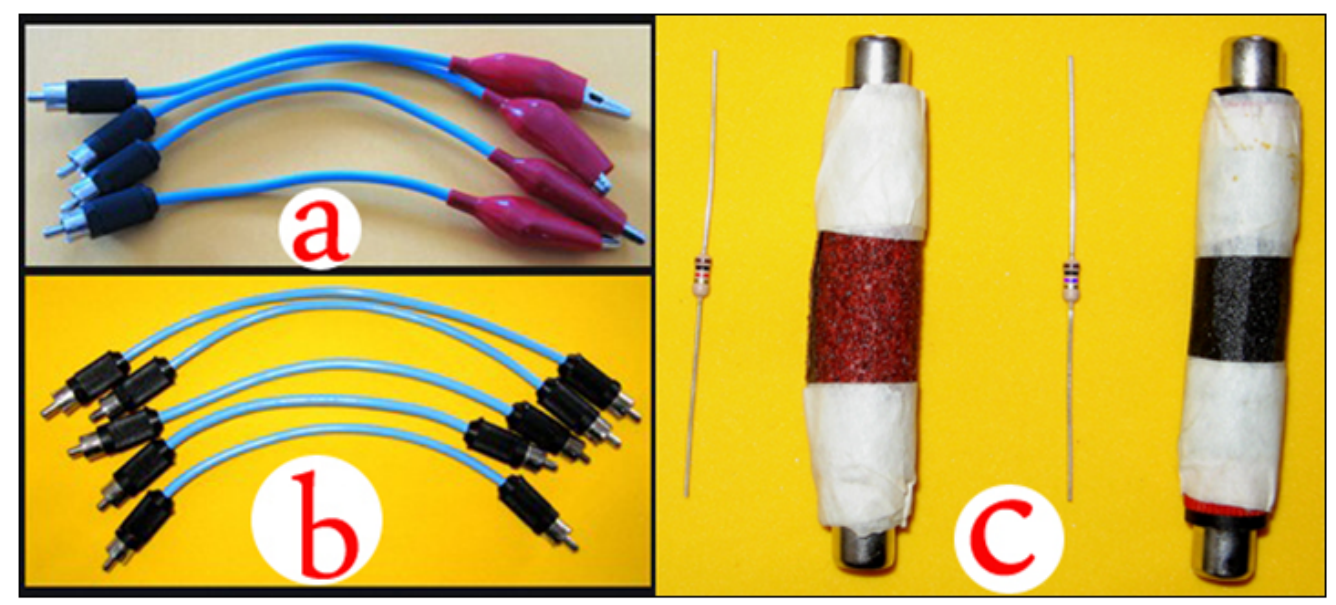

Figura 7: Conectores e Resistores.

O "resistor modificado"possuía um resistor no interior do cilindro. Os conectores tipo "pino banana"foram substituídos por conectores RCA utilizados em dois tipos de fios para conexões entre circuitos. Um deles com extremidade jacaré-RCA (figura 7a) e outro com extremidades RCA-RCA (figura 7b).

As maquetes dos fios condutores (figura $8 b$ ) foram unificadas em um único cilindro de papel, oferecendo condições para que se realizassem analogias com fios submetidos, ou não, a uma diferença de potencial elétrico. Composta por um canudo de papelão, esta maquete foi projetada para ser aberta (figura 8a). Em seu interior havia esferas de isopor fixas, representando os átomos e grãos de milho, que representam os elétrons. Estes também foram representados pelos dedos dos estudantes ao perpassarem o canudo de ponta a ponta. 


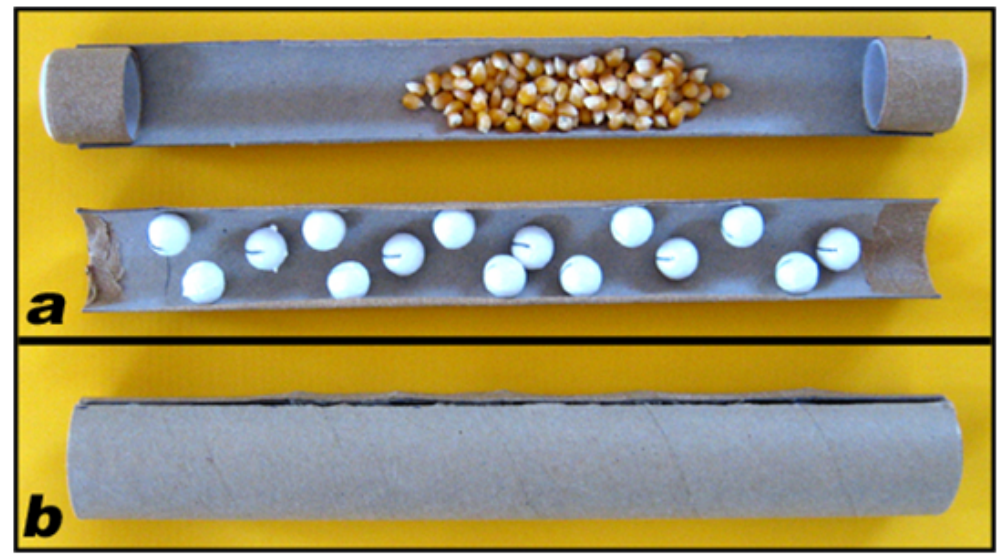

Figura 8: Maquete fio condutor.

Outras duas novas maquetes desenvolvidas. Consistem em dois tubos de papel-cartolina, com grãos de feijão no seu interior. As analogias com as diferentes resistências elétricas foram feitas através da aderência externa.

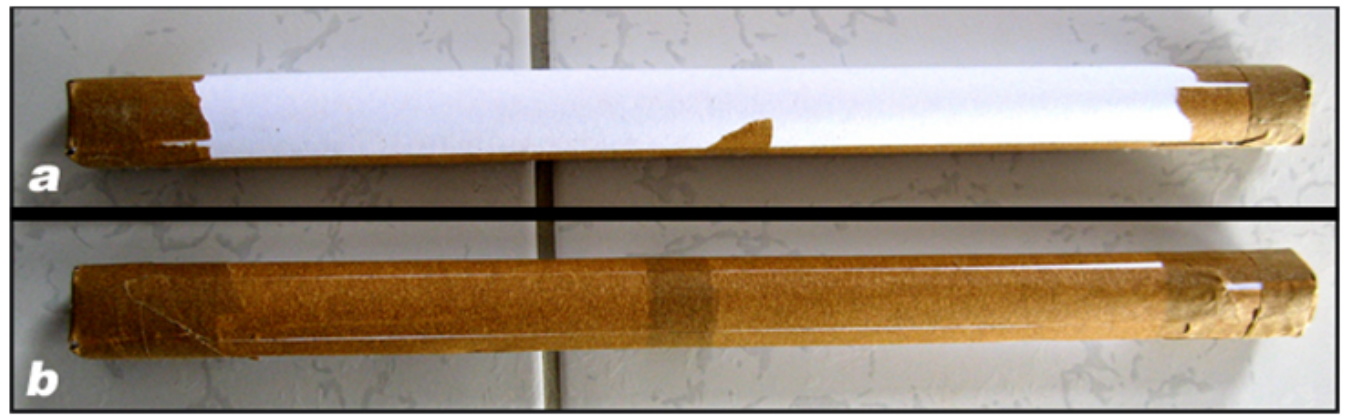

Figura 9: Maquete resistência elétrica.

A "maquete a"referente à menor resistência elétrica (figura 9a), apresentava-se externamente lisa. Já, a "maquete b", relativa à maior resistência elétrica (figura 9b), possuía fita crepe ao seu entorno. A resistência mecânica oferecida ao movimento dos grãos na "maquete a"decorria do atrito existente entre os grãos e o papel-cartolina. Na "maquete b", a resistência mecânica procedia de rugosidades feitas com fita crepe, inseridas em toda a sua extensão interna. $\mathrm{O}$ movimento dos grãos era percebido de maneira tátil e auditiva através do atrito com a cartolina.

A seguir mostraremos os circuitos montados pelos estudantes; 


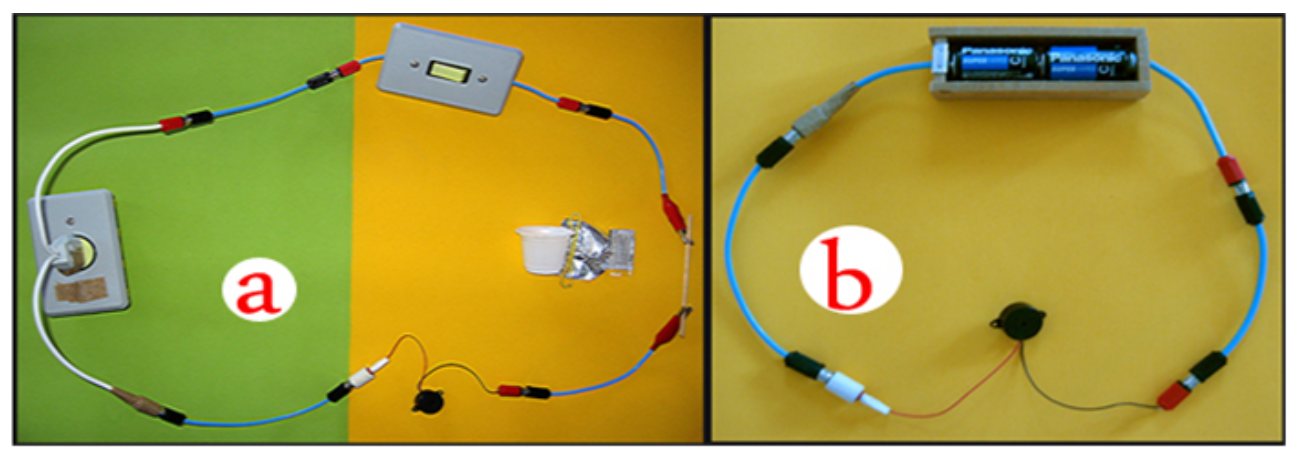

Figura 10: Condutividade Elétrica.

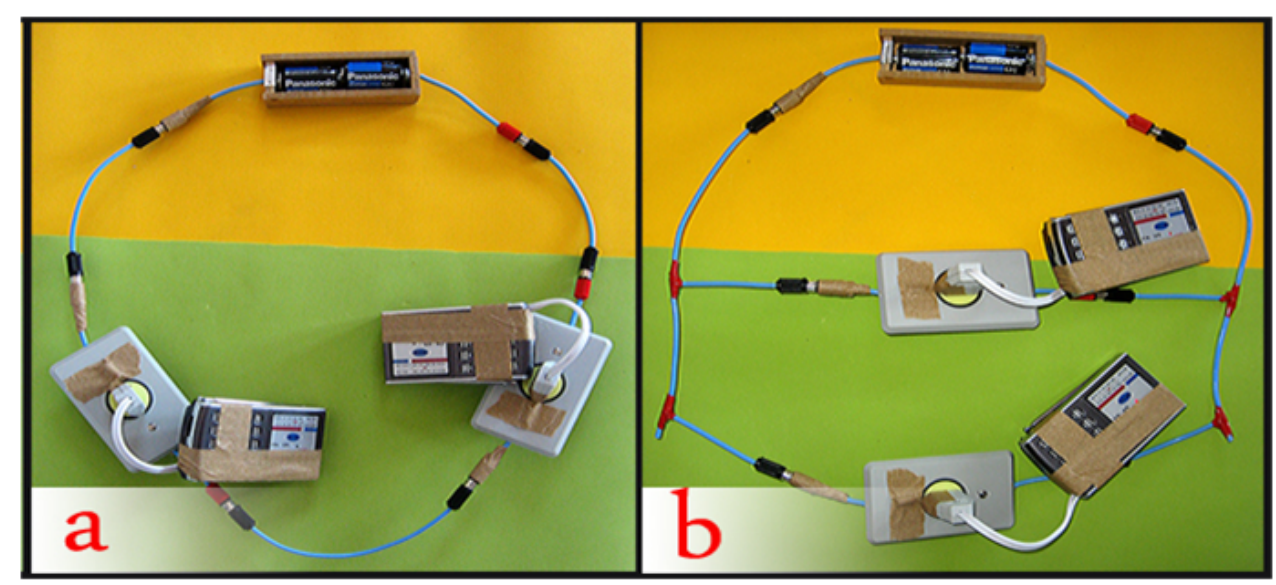

Figura 11: Circuitos série e paralelo.

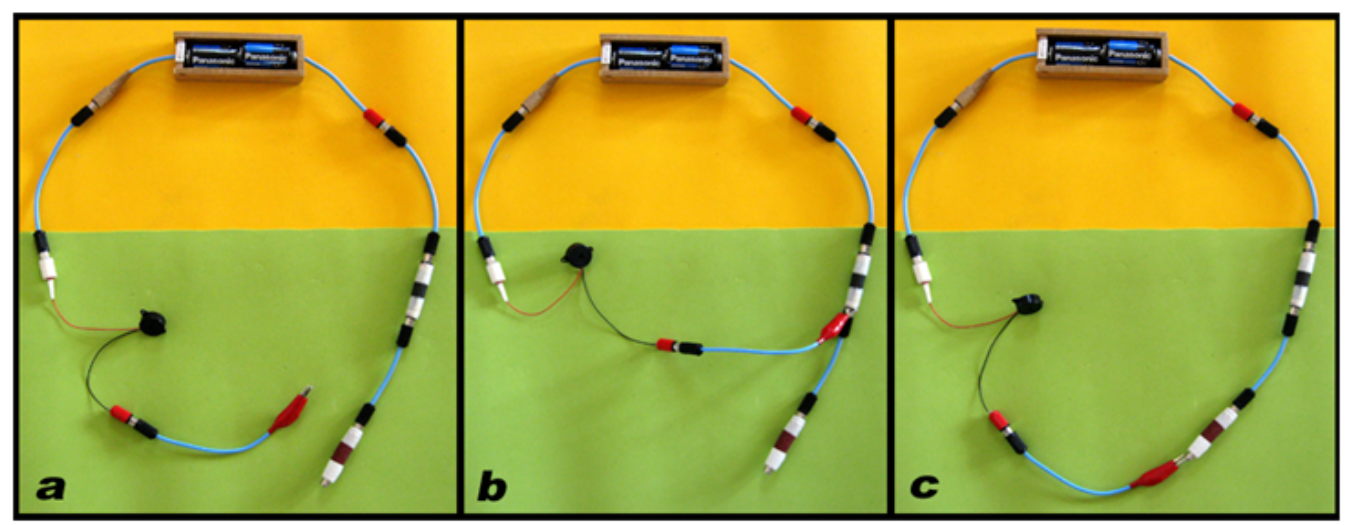

Figura 12: Atividade com circuitos série.

A figura 10a, mostra o circuito construído para identificar a condutividade elétrica dos materiais e abertura e fechamento do circuito. Na figura 10b, está o circuito no qual os alunos praticaram a inserção do buzzer, atentando para sua polaridade definida. Os circuitos série e paralelo estão representados nas figuras 11a e 11b, onde foi evidenciada a constância da corrente elétrica no primeiro e da diferença de potencial elétrico no segundo. A figura 12 retrata a atividade em que se trabalhou a relação entre resistência elétrica e corrente 
elétrica, tornando nítido que o aumento do valor da primeira resulta na redução do valor da segunda, percebido na atividade, por meio da variação sonora emitida pelo buzzer.

Caso haja interesse dos leitores deste trabalho, os relatos e análises, dos alunos com deficiência visual, com relação as atividades aplicadas podem ser encontrados em Evangelista (2019).

\section{Considerações Finais e Perspectivas}

A ordem da sequência didática apresentou melhoras. Ao tratar dos conceitos circuitos abertos e fechados juntamente com a condutividade dos materiais favoreceu-se a interrelação conceitual, auxiliando na apreensão dos saberes. Por trabalhar o conceito corrente elétrica mais cedo, foi possível recorrer as terminologias científicas com maior frequência, auxiliando inclusive na contextualização dos fenômenos, estimulado por meio dos circuitos elétricos residenciais.

Através dos questionários, além de se detectar as assimilações e os equívocos, reforçouse os assuntos pendentes através de explicações e constantes recapitulações conceituais, resultando na redução das disparidades conceituais e minimização das dificuldades de aprendizado oriundas da ausência de um estudo extra-classe. A utilização de textos didáticos (GREF, 1991), auxiliou na inserção e compreensão da terminologia científica. A "leitura interativa"demonstrou-se eficaz, visto que, ao atribuir uma condição participativa aos estudantes, mantinham-se atentos durante a leitura, relacionando os conceitos lidos com ações concretas, requisitadas simultaneamente pelo professor.

A constatação das subcategorias de Apreensão do Conteúdo mostraram que os alunos apresentaram uma participação ativa no processo de ensino e aprendizagem, expressando suas ideias, provocando questionamentos e promovendo situações de conflitos e compartilhamentos conceituais. A identificação das subcategorias de Descrição do Material mostrou que houve uma boa aceitação dos materiais por parte dos alunos, que manusearam e realizaram as ações solicitadas sem maiores dificuldades. Verificou-se ainda que, o fato de os materiais terem sidos apresentados separadamente, permitiu um reconhecimento tátil mais rápido, atribuindo ainda maior liberdade durante a montagem dos circuitos. Como consequência, os alunos propuseram mais atividades espontaneamente.

Constatou-se que para o processo de caráter inclusivo, tanto os materiais quanto os procedimentos apresentaram-se potencialmente capazes de serem aplicados junto a alunos com e sem deficiência visual estudando no mesmo ambiente do ensino regular, visto que, o tempo despendido para o reconhecimento dos materiais foi reduzido, a liberdade atribuída ao aluno aumentada, permitindo a realização de ações voluntárias e sugestões espontâneas de novas configurações para os circuitos. Oportunizaram-se ainda, situações onde o "erro", durante a montagem dos circuitos, também fosse utilizado para fomentar soluções. Estas, por sua vez, pareceram potencializar o poder argumentativo discente, que constantemente mencionavam eventos e materiais já trabalhados. Além disso, as relações com o cotidiano e a fixação dos termos científicos foram verificadas com maior frequência.

Porém, alguns limites percebidos durante a realização desta pesquisa precisam ser apontados. Não foi utilizada a aplicação de equações matemáticas, contudo, acredita-se que o primeiro passo foi dado. A partir do que foi trabalhado, torna-se possível sugerir 
situações hipotéticas para serem resolvidas matematicamente. As recomendações quanto aos materiais e procedimentos metodológicos precisam ser postas em prática para verificar seu real potencial. Além disto, desenvolver critérios referentes às técnicas avaliativas, que sejam condizentes as necessidades e especificidades dos estudantes, são necessárias para poder mensurar mais detalhadamente o desenvolvimento educacional. Ademais, durante a presença na ACIC verificou-se que os respectivos alunos tinham contato direto com computadores pessoais, tornando nítida a necessidade de investigar estratégias que permitam utilizar as tecnologias e os multimeios como auxílio no processo de ensino e aprendizagem destes sujeitos. Pode-se salientar ainda, a necessidade de transpor didaticamente os conteúdos trabalhados, para que permitam promover o desenvolvimento do pensamento crítico, criando procedimentos metodológicos que motivem a inserção da literatura específica, no intuito de auxiliar a assimilação conceitual e terminológica.

Nesta perspectiva, este trabalho procurou mostrar que é possível tratar conceitos complexos e/ou específicos com estudantes com deficiência visual e que, potencialmente falando, $\mathrm{o}$ ensino destes, juntamente com alunos videntes, parece perfeitamente plausível.

\section{REFERÊNCIAS}

ALVES FILHO P. J. Atividades Experimentais: do Método à Prática Construtivista. 302 f. Tese (Doutorado em Educação: Ensino de Ciências Naturais) Universidade Federal de Santa Catarina, 2000.

BRASIL. Ministério da Educação. Lei de Diretrizes e bases da educação (n.939496). Brasília, DF, 1996. Disponível em < http://portal.mec.gov.br/arquivos/pdf/ldb.pdf>. Acesso em julho de 2017.

CAMARGO, E. P. O Ensino de Física no Contexto da Deficiência Visual: elaboração e Condução de Atividades de Ensino de Física para Alunos Cegos e com Baixa Visão. 272 f. Tese (Doutorado em Educação para a Ciência) - Faculdade de Educação, Universidade Estadual de Campinas, 2005.

CARNEIRO, Eudocha et al. EXPERIMENTO ADAPTADO PARA ESTUDANTES COM DEFICIÊNCIA VISUAL: ESTUDO DA RELAÇÃO SOLUBILIDADE VERSUS TEMPERATURA/Experiment adapted for visually disabled students: study of relation between solubility and temperature. Revista Aretél Revista Amazônica de Ensino de Ciências, v. 9, n. 18, p. 173-181, 2017.

CAT-Comitê, De Ajudas Técnicas. Ata da Reunião VII, de dezembro de 2007 do Comitê de Ajudas Técnicas. Secretaria Especial dos Direitos Humanos da Presidência da República (CORDE/SEDH/PR), 2007.

COLL, C. et. al. Os conteúdos na reforma: ensino e aprendizagem de conceitos, procedimentos e atitudes. Porto Alegre: Artes Médicas, 1998. 
DE SOUZA, Flaviane; PALMA, Francisco. PROPOSTA DE UM SISTEMA DE REPRESENTAÇÃO DA REFLEXÃO DA LUZ EM UM ESPELHO ESFÉRICO PARA ALUNOS COM DEFICIÊNCIA VISUAL/A proposal of a representation of light reflection in spherical mirrors for teaching students with visual impairment. Revista Areté I Revista Amazônica de Ensino de Ciências, v. 9, n. 20, p. 67-71, 2017.

DRIVER, R. Psicologia cognitiva y esquemas conceptuales de los alumnos. Enseñanza de lãs Ciências, v.4, n.1, p.3-15, 1986.

EVANGELISTA, F. L. O ensino de corrente elétrica a alunos com deficiência visual. 2008.

EVANGELISTA, F. L. Física para pessoas com deficiência visual: ensino de corrente elétrica. 1 ed. Concórdia: Jucimar Peruzzo, 2019. v. 1. 134p.

FACCIO, Miguel et al. Força e movimento: concepções alternativas no Ensino Superior. Revista Educar Mais, v. 3, n. 2, p. 173-191, 2019.

FREITAS, Wesley Ricardo de Souza; JABBOUR, Charbel José Chiappetta. O Estudo de Caso(s) como Estratégia de Pesquisa Qualitativa: fundamentos, roteiros de aplicação e pressupostos de excelência. www. abepro. com. br. Acesso em, v. 12, p. 12, 2016.

GALVÃO FILHO, Teófilo Alves. Tecnologia assistiva para uma escola inclusiva: apropriação, demanda e perspectivas. 2009.

GRECA, I. M.; MOREIRA, M. A. Além da detecção de modelos mentais dos estudantes: uma proposta representacional integradora. Investigações em Ensino de Ciências, v. 7, n.1, 2002. Disponível em <http://www.if.ufrgs.br/public/ensino/revista.htm>. Acesso em julho de 2017.

GRUPO DE REELABORAÇÃO DO ENSINO DE FÍSICA. Eletromagnetismo. São Paulo: Edusp, 1991. Disponível em < http:/ / fisica.cdcc.sc.usp.br/GREF/livros.html>. Acesso em julho de 2017.

LIMA, Maria da Conceição Barbosa; DE CASTRO CATARINO, Giselle Faur. Formação inicial de professores de Física: a questão da inclusão de alunos com deficiências visuais no ensino regular. Ciência Educação, v. 18, n. 1, p. 81-98, 2012.

MASINI, E. F. S. Impasses sobre o Conhecer e o Ver. In: O perceber e o relacionar-se do deficiente visual: orientando professores especializados. Brasília: CORDE, 1994.

OLIVEIRA, Dirlene Aparecida de. Concepções espontâneas sobre o conceito de movimento entre estudantes de física (mecânica) da UFFS-Campus Laranjeiras do Sul. 2018.

PIETROCOLA, M. Construção e realidade: o papel do conhecimento físico no entendi- 
mento do mundo In: PIETROCOLA, M. (Orgs). Ensino de Física: conteúdo, metodologia e epistemologia numa concepção integradora. Florianópolis: Editora da UFSC, 2001.

PIMENTEL, Andréia Guerra; ARAGON, Glauca Torres. JOGO EDUCACIONAL E MEIO AMBIENTE: ADAPTAÇÃO DE UM LIVRO-JOGO PARA ALUNOS COM DEFICIÊNCIA VISUAL. Revista Aretél Revista Amazônica de Ensino de Ciências, v. 11, n. 24, p. 156-165, 2019.

SANTOS, Pâmela Mello dos et al. Evolução biológica na perspectiva de estudantes do ensino médio: das concepções espontâneas aos saberes escolares. 2017.

SIPEC, I. Um diálogo sobre as concepções alternativas presentes no ensino das ciências. Arquivos do Museu Dinâmico Interdisciplinar, v. 21, n. 3, p. 90-101, 2017.

SOLIS VILLA, R. Ideas intuitivas y aprendizage de las ciencias. Enseñanza de las Ciencias, v.2, n.2, p.1-19, 1994.

SOUZA, O. S. Nas entrelinhas da inclusão escolar de alunos com necessidades educativas especiais: o desafio da formação docente. 194 f. Tese (Doutorado em Educação) Faculdade de Educação, Universidade Federal do Rio Grande do Sul, 2002.

VIENNOT, L. Spontaneous reasoning in elementary dynamics. European Journal of Science Education, v.1, n.2, p.205-221, 1979.

VYGOTSKI, L.S. Obras escogidas. Madrid: Editora Pedagógica, 1998. 